\title{
Hyperglycosylated hCG in a Group of Iraqi Patients with Gestational Trophoblastic Disease
}

\author{
Maad Mehdi Shallal ${ }^{1}$, Najmah Mahmood Miran ${ }^{2}$, Uhood Abbas Obed $^{3}$ \\ FICOG, Baghdad Teaching Hospital, Professor at College of Medicine/University of Baghdad
}

FICOG, CABOG, DOG, Baghdad Teaching Hospital, Lecturer at College of Medicine/University of Baghdad

MBChB, Baghdad Teaching Hospital

\begin{abstract}
Background: Hyperglycosylated hCG a newly discovered variant of hCG which can be used as a predictor of invasion of trophoblastic cells in patient with gestational trophoblastic disease. Objectives: To measure hyperglycosylated human chorionic gonadotrophin and to assess how far it can be used as predictor of invasion in invasive mole and choriocarcinoma. Study design: Casecontrol study. Setting: Gynecological department in Baghdad Teaching Hospital from January 2016 to January 2017. Patient and Methods: 60 women were enrolled in this study 30 of them were with gestational trophoblastic disease $($ no. $=30)$ the remainder were normal pregnancy (no. $=30), h C G-H$ level was measured in both groups. $\underline{\text { Results: }}$ : Mean serum hCG-H level was significantly higher in patients with gestational trophoblastic disease compared to control women $(460.5 \pm 168.35,206.8 \pm 19.99)$ respectively with $p$ value $<$ 0.05. Mean serum hCG-H level was significantly higher in patients with gestational trophoblastic disease Invasive mole and chriocarcinoma compared to patient with molar pregnancy. Before evacuation $(772.11 \pm 184.08,398.27 \pm 65.86)$. After evacuation $(550.52 \pm 146.15,340.40 \pm 85.61)$. With $p$ value $<0.05$. Conclusion: 1) Serum hCG-H level was higher in patients who had invasive mole and patients with choriocarcinoma than patients with gestational trophoblastic disease, so it can be used as a predictor of invasion in patients with invasive mole and choriocarcinoma. 2) Serum hCG-H level can be used in patient with abnormal $\beta$ - hCG after evacuation when it is slowly decreasing or plateau. 3) It is better to measure the ratio hCG-H/total hCG and using uniform method test and units so we can understand the actual changes that happen in invasion.
\end{abstract}

Keywords: Hyperglycosylated hCG, Invasive mole, choriocarcinoma

\section{Introduction}

Hydatidiform mole (partial or complete), is the most common type of gestational trophoblastic disease. Gestational trophoblastic disease consist of disorders of placental development (hydatidiform mole) and gestational trophoblastic neoplasia (choriocarcinoma, epithelioid trophoblastic tumor and placental site trophoblastic tumor $)^{(1,}$

2). These trophoblastic lesions produce human chorionic gonadotrophin (hCG), which can be used as a marker for the presence of persistent or progressive trophoblastic disease ${ }^{(3)}$

Persistent gestational trophoblastic disease after a complete or partial mole is detected by serum hCG titers which fail to return to normal level. The risk of persistent gestational trophoblastic disease is higher with complete mole. Up to $20 \%$ or more of patients with complete mole need further therapy, usually by chemotherapy, for a plateau or increase in the serum hCG titer following evacuation ${ }^{(2,4,5)}$. About $2 \%$ to $3 \%$ of patients with complete mole will develop choriocarcinoma. Meanwhile, the risk of persistent gestational trophoblastic disease is much lower among patients with partial mole, as it occurs in $0.5 \%$ to $5 \%$ of cases ${ }^{(2,6,7)}$.Most of the cases of persistent gestational trophoblastic disease represented as persistent mole within the uterine cavity or invasive mole in the myometrium. Less often a patient has invasive mole with villi and trophoblast that migrates to the lungs, vagina, vulva, or liver metastases that are not biopsied for classification.

The malignant form of gestational trophoblastic disease is choriocarcinoma. It is much more likely than other types of gestational trophoblastic disease to grow rapidly and spread to organs distant from the uterus. Half of all gestational choriocarcinomas start as molar pregnancies ${ }^{(8)}$.

Hyperglycosylated human chorionic gonadotropin, (hCG-H) has been reported by many studies to have a very different oligosaccharide structure from that of regular hCG

So far, tests for measuring hCG-H have independent uses from that of regular hCG. hCG-H is supposed to be a cytokine rather than a hormone because of its functions as autocrine rather than endocrine and modulating apoptosis of trophoblastic cell ${ }^{(9)}$.

The first biological activity of hCG was delivered at 1920 and confirmed and elaborated in the next years ${ }^{(10,11)}$. While pregnancy happens, hCG releases from LH in promoting production of progesterone by corpus luteal cells in the ovary so that to prevent menstrual bleeding. The function of hyperglycosylated $\mathrm{hCG}$, and metalloproteinase promoting activity, blocking apoptosis, suggests that hyperglycosylated hCG an antagonist of $\mathrm{TGFb}$ receptor controlled functions in cytotrophoblast cells.

These pathways seems very likely from many studies of placental implantation, cytotrophoblast cells and metalloproteinase and placental invasion biology, cytotrophoblast cell apoptosis, that $\mathrm{TGFb}$ receptor is involved in these actions (12,13,14). In addition, hyperglycosylated hCG acts by antagonizing a cytotrophoblast $\mathrm{TGFb}$ receptor, seemingly blocking apoptosis and promoting invasion by metalloproteinases. This is consistent with hyperglycosylated hCG having a function of promoting implantation early in pregnancy $(15,16)$. Research clearly shows that hyperglycosylated hCG acts on 


\section{International Journal of Science and Research (IJSR) \\ ISSN (Online): 2319-7064}

Index Copernicus Value (2015): 78.96 | Impact Factor (2015): 6.391

choriocarcinoma cells enhancing invasion. Laboratory experiments demonstrate that antibody to hyperglycosylated hCG, antibody B152, blocks hyperglycosylated hCG promotes growth of cytotrophoblast cells, at implantation and in choriocarcinoma ${ }^{(17,18)}$.

Different articles investigating free $b$-subunit as a prognostic marker in cancer, 12 of 13 studies show a clear relationship between expression of hCG free b-subunit and poor prognosis $(15,19)$. Together these studies indicate that expression of free b-subunit leads to a negative result in human malignancies. Now, many reports demonstrate that free b-subunit may have a specific role in malignant transformation of cells ${ }^{(13,20)}$. Free b-subunit has a major role in the biochemistry of non gestational neoplasm, either as a promoter causing poor outcome of malignancy, or as an element concerned in malignant transformation. In fact, efforts are now being directed toward the use of different $\mathrm{hCG} b$ subunit derivatives as vaccines in the management of non-gestational malignancies. The association of free $b$ detection and poor prognosis, in combination with site specific hCG b-subunit vaccine technology suggests a possible route to the development of adjuvant cancer therapies specifically targeting patients with non-gestational tumors that produce free $b$-subunit. Both free $b$ and hyperglycosylated hCG promote growth of cancer cell and malignancy ${ }^{(17,21)}$,

Similarly, both free b and hyperglycosylated hCG function by antagonizing or blocking apoptosis causing cell growth.

Gestational trophoblastic disease - hCG-H promotes growth and invasion of trophoblast ${ }^{(17,18)}$. The invasion could be controlled, as in implantation of pregnancy and complete/partial mole, or uncontrolled, as in gestational trophoblastic neoplasia (invasive mole and choriocarcinoma). However, hyperglycosylated hCG accounts for the great proportion of total hCG forms produced at the times of trophoblast invasion. It produced in both conditions at the time of trophoblast invasion at implantation as well as the trophoblast invasion that marks choriocarcinoma cases $(22,23,24)$. Furthermore, the amount that made in the absence of trophoblast invasion represented small proportions of hCG-H ( $<2 \%$ of total hCG). So far, the presence of significant hCG-H is an absolute marker of invasion or malignancy and the requirement for chemotherapy $(23,24,25)$

\section{Patients and Methods}

This was a case-control study which is done to determine the difference of hCG-H between patients with molar pregnancy and control group as well as to determine the level of hCG$\mathrm{H}$ by evacuation of molar pregnancy at Baghdad Teaching Hospital from February 2016 to February 2017.

Thirty pregnant women with vaginal bleeding have been received in department of gynecology of Baghdad Teaching Hospital. All the thirty patients have been sent for ultrasound and serological test of hCG-H and $\beta$-hCG before and after evacuation for two times of molar pregnancy. The biopsies have been sent for histology to reach the diagnosis. Another thirty pregnant women with no signs and symptoms of molar pregnancy have been conducted in this study.

a) Inclusion criteria for patients

1. Pregnant women with suspected signs and symptoms of molar pregnancy.

2. Diagnostic ultrasonic features of molar pregnancy.

3. Elevated titre of $\beta$-hCG.

b) Exclusion criteria for patients

1- patient with molar pregnancy who are on chemotherapy.

c) Inclusion criteria for control

1. Pregnant women with no signs and symptoms of molar pregnancy.

2. Same age groups for patients with molar pregnancy.

d) Exclusion criteria for control

Pregnant women with gestation age $\geq 13$ weeks.

Pregnant women with multiple pregnancy.

Pregnant women with medical disease.

The dependent variable for this study was the study groups; patients with molar pregnancy and control. The independent variables of this study comprised: patients' age, residence and educational levels as well as patients' parity, abortion and mode of delivery. Serological level of hCG-H has also been detected. Human Hyperglycosylated chorionic gonadotrophin (hCG-H) enzyme-linked immune sorbent assay (ELISA) Kit is used for this study. This kit has used to assay the Hyperglycosylated chorionic gonadotrophin (hCG$\mathrm{H}$ ) in the sample of blood plasma, human serum and other related biological liquid. This ELISA kit works based on biotin double antibody sandwich technology to assay Human Hyperglycosylated chorionic gonadotrophin (hCG-H). It is achieved by adding Hyperglycosylated chorionic gonadotrophin $(\mathrm{hCG}-\mathrm{H})$ to wells that are pre-coated with Hyperglycosylated chorionic gonadotrophin (hCG-H) monoclonal antibody and then incubate. After a period of incubation, there will be adding of anti Hyperglycosylated chorionic gonadotrophin (hCG-H) antibodies labeled with biotin to unite with Streptavidin-HRP, which forms the immune complex. Furthermore, it will be removing of unbound enzymes after incubation and washing, then adding of substrate A and B. as a result, the solution will turn blue and change to yellow with the effect of acid. So far, the shades of solution and the concentration of Human Hyperglycosylated chorionic gonadotrophin (hCG-H) are positively correlated.

$\beta$-HCG has a double immunoenzymetric analysis of intact molecules and subunit of hCG beta, intact hCG molecule and beta subunit present in the test sample are bound to the monoclonal antibody immobilized on the magnetic grains and then markedly different antigenic site on the beta subunit bound to an enzyme-labeled monoclonal antibody. Magnetic grains are washed free of unbound, enzymelabeled monoclonal antibodies and thereafter incubated with the fluorogenic substrate, 4-methylumbeliferylfosfátem (4MUP). Amount of enzyme labeled monoclonal antibody which binds to the particles is directly proportional to the concentration $\beta \mathrm{HCG}$ in the test sample. 


\section{International Journal of Science and Research (IJSR) \\ ISSN (Online): 2319-7064}

Index Copernicus Value (2015): 78.96 | Impact Factor (2015): 6.391

Data Analysis

The statistical analysis has been conducted by using of Statistical Package of Social Sciences (SPSS 20). Continuous variables were presented as mean \pm standard deviation. Categorical variables were presented as frequency and percentages. Pearson's $\left(X^{2}\right)$ test was used to find the association between two categorical variables. Independent sample t-test was used to compare between two continuous variables. Paired t-test was used to compare between two readings of same continuous variable. $P$ value of $\leq 0.05$ was considered as significant.

\section{Results}

The mean age of patients with molar pregnancy and control were $(28.07 \pm 8.19)$ and $(30.80 \pm 5.32)$ years old respectively.

Figure 1 shows the comparison of study groups by residence, $(90.0 \%)$ and $(56.7 \%)$ of patients with molar pregnancy and control were from urban areas.

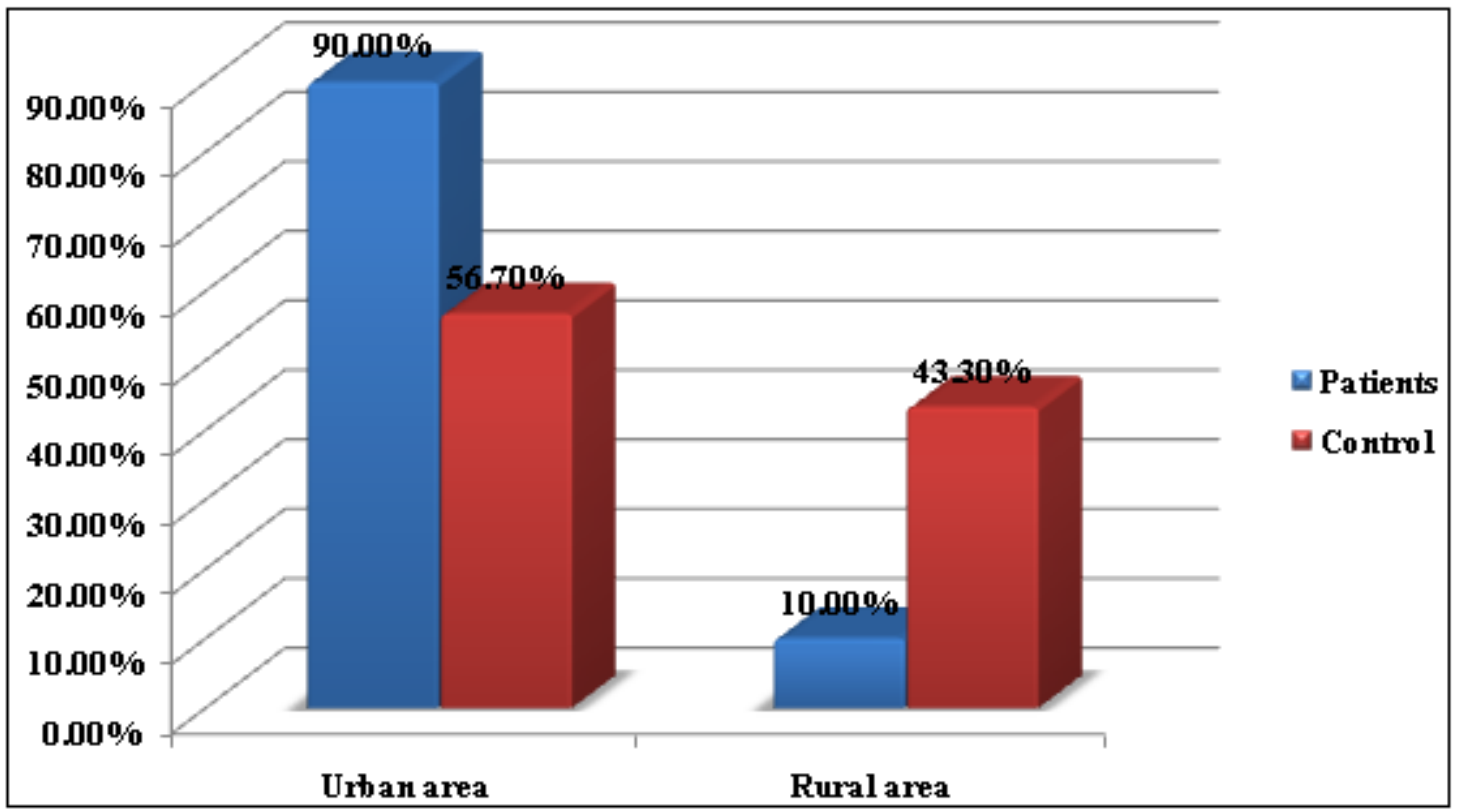

Figure 1: Comparison of study groups by residence

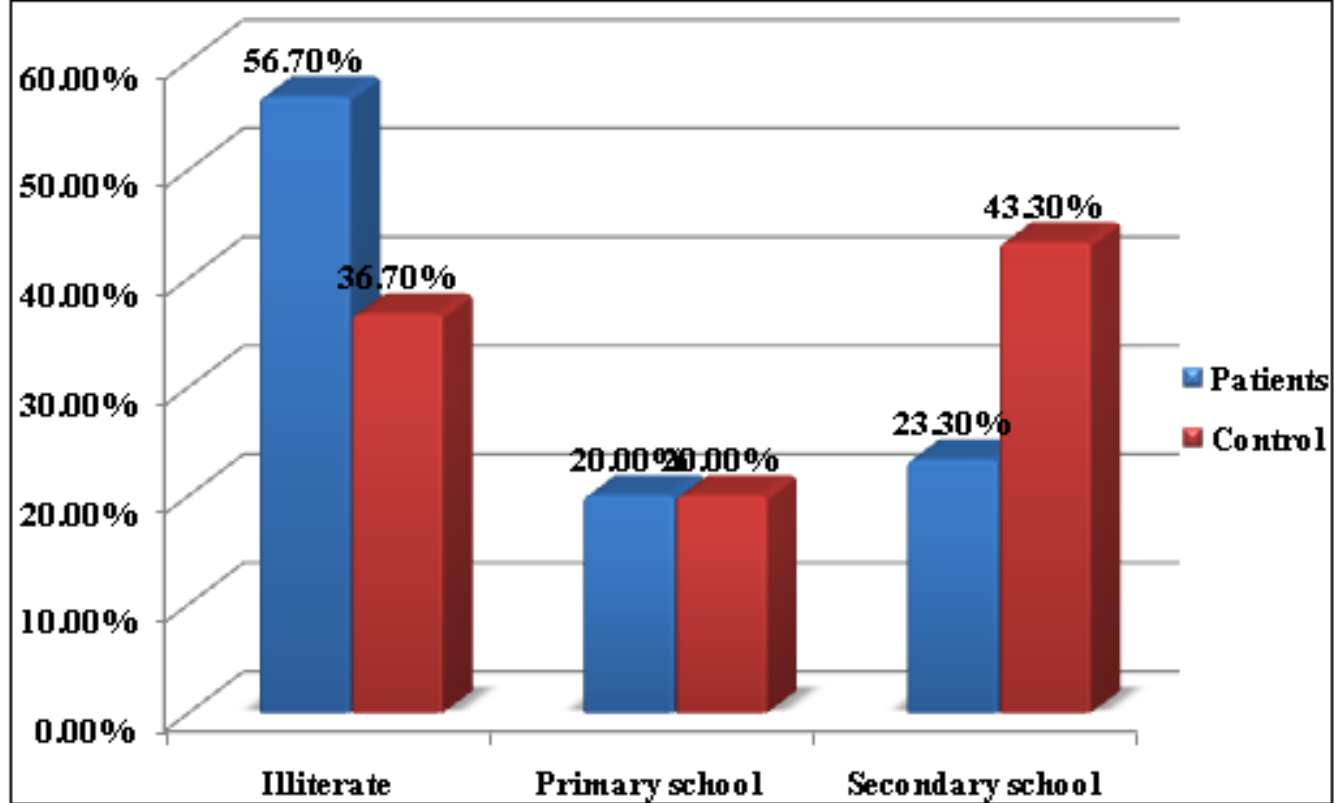

Figure 2: Compare the study groups by educational levels, (56.7\%) and (36.7\%) of patients with molar pregnancy and control were illiterate

Figure 2: Comparison of study groups by educational levels 


\section{International Journal of Science and Research (IJSR) \\ ISSN (Online): 2319-7064 \\ Index Copernicus Value (2015): 78.96 | Impact Factor (2015): 6.391}

Table 1: Comparison of patients with molar pregnancy and control by parity, abortion and mode of delivery

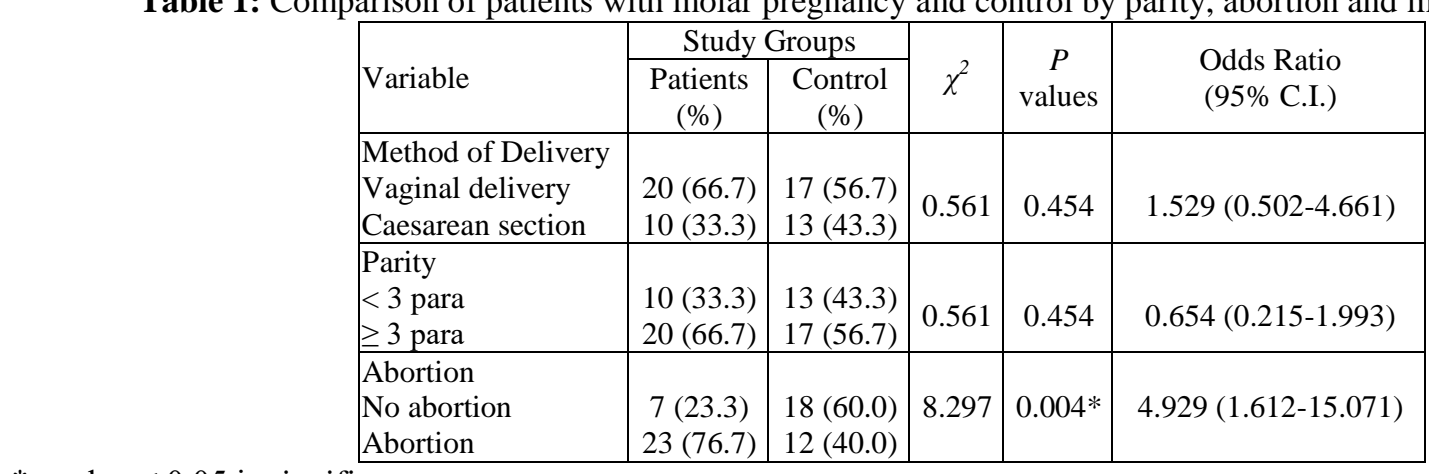

$*$ p value $\leq 0.05$ is significant

There was significant difference between patients and control by abortion. Pregnant women with molar pregnancy were four times more likely to have abortion.

Table 2: Mean difference of Patients with Molar Pregnancy and Control by hCG-H

\begin{tabular}{|c|c|c|c|c|c|c|}
\hline & Group & number & Mean & S.D & t-test & P value \\
\hline \multirow{2}{*}{ hCG-H } & $\begin{array}{c}\text { Patient with } \\
\text { molar pregnancy }\end{array}$ & 30 & 460.57 & 168.35 & \multirow{2}{*}{8.198} & $<0.001 *$ \\
\cline { 2 - 7 } & Control & 30 & 206.81 & 19.99 & & \\
\hline
\end{tabular}

$* \mathrm{p}$ value $\leq 0.05$ is significant

There was significant mean difference of hCG-H by patients with molar pregnancy and control.

Figure 3 demonstrate the division of patients by diagnosis. $(83.9 \%)$ of patients were molar pregnancy. Meanwhile, $(12.9 \%)$ and $(3.2 \%)$ of patients were invasive molar pregnancy and choriocarcinoma, respectively.

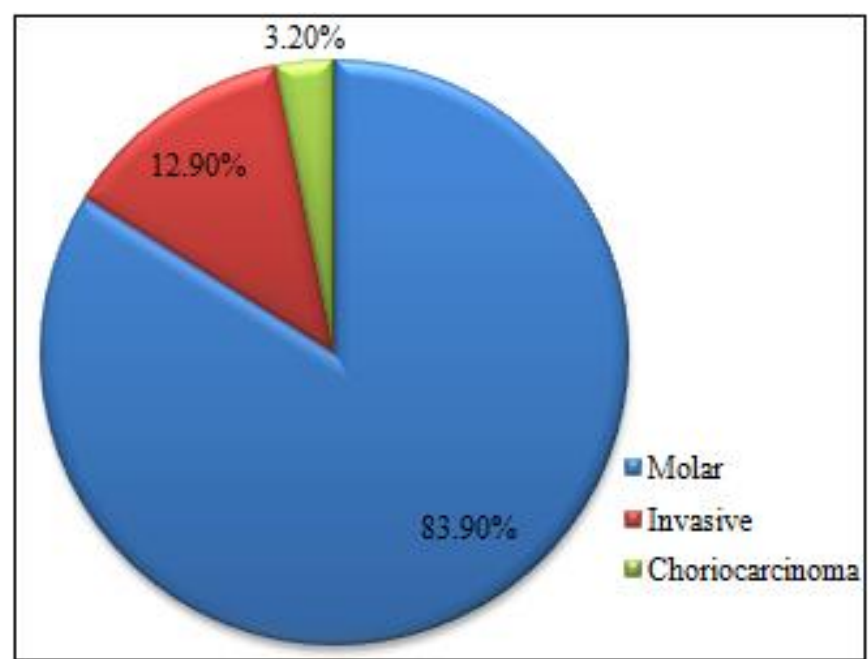

Figure 3: Distribution of Patients with Molar Pregnancy by Diagnosis

Table 3: Mean Difference of HCG-H before and after Evacuation by Patients with Molar Pregnancy, Invasive and Choriocarcinoma

\begin{tabular}{|c|c|c|c|c|c|}
\hline & hCG-H & Mean & S.D & $\begin{array}{c}\text { Paired } \\
\text { t-test }\end{array}$ & $\mathrm{P}$ value \\
\hline \multirow{2}{*}{$\begin{array}{c}\text { Molar } \\
\text { pregnancy }\end{array}$} & Before 2 weeks & 398.27 & 65.86 & \multirow{2}{*}{3.757} & \multirow{2}{*}{$0.001 *$} \\
\hline & After 2 weeks & 340.40 & 85.61 & & \\
\hline \multirow[b]{2}{*}{$\begin{array}{c}\text { Invasive and } \\
\text { Choriocarcinoma }\end{array}$} & Before 2weeks & 772.11 & 184.08 & \multirow[b]{2}{*}{3.276} & \multirow[b]{2}{*}{$0.005 *$} \\
\hline & After 2 weeks & 550.52 & 146.15 & & \\
\hline
\end{tabular}

${ }^{*} \mathrm{p}$ value $\leq 0.05$ is significant
There were significant mean differences of hCG-H for molar pregnancy as well as Invasive and Choriocarcinoma before and after evacuation.

\section{Discussion}

Gestational trophoblastic disease has been reported to be a unique group of uncommon but interrelated conditions derived from placental trophoblasts, with a variety of histological appearances and clinical behaviors (26). However, the in vitro models for human trophoblasts were initially established more than three decades ago from isolated choriocarcinoma ${ }^{(27)}$. Nowadays, it is found to be extremely valuable for the study of the molecular, cellular and endocrine aspects of human trophoblasts. Although, molecular analysis can only be determined by the nuclear DNA origin of complete hydatidiform mole and allow defining the patients with higher risk of malignant transformation usually to gestational choriocarcinoma ${ }^{(28.29)}$. However, clinicians often fail to consider the possibility of trophoblastic disease due to its low incidence rate and its non-specific clinical manifestations.

Gestational trophoblastic disease has significantly higher incidence in Asian countries ${ }^{(30)}$; it is about 1.95 times higher than non-Asian population. Many studies in Singapore and Karachi revealed that, the high incidence of Gestational trophoblastic disease in Asia is generally attributed to malnutrition and low socioeconomic status ${ }^{(31)}$ as well as dietary etiology; in addition the disease is common in the extreme of reproductive ages ${ }^{(32,33)}$ which agree with our study result . The cause is unknown. The prevalence of gestational trophoblastic disease in different studies from Africa was around 3.58 to 4.7 per 1000 in Nigeria ${ }^{(34,35)}$. However, it is much higher than incidences of 1 per 1000 , 1.3 per 1000 , and 2 per 1000 pregnancies reported in the United States, the United Kingdom and Japan respectively

\section{Volume 6 Issue 7, July 2017 www.ijsr.net}




\section{International Journal of Science and Research (IJSR) \\ ISSN (Online): 2319-7064}

Index Copernicus Value (2015): 78.96 | Impact Factor (2015): 6.391

$(36,37,38)$. The reason for low prevalence in industrialized countries compared to developing countries may be due to differences in the denominators (per pregnancies versus per deliveries) and most studies in developing countries were hospital based ${ }^{(39)}$.

The diagnosis of trophoblastic disease was depend upon the clinical features, hCG titer, high resolution vaginal ultrasonography and histopathology.

However, serum hCG and ultrasonography are the sensitive detectors of trophoblastic disease. These tests are simple, inexpensive, non-invasive and give a quick results. Ultrasound is the method of choice for differentiating normal from abnormal pregnancy in first trimester. When the sonographic appearance is correlated with the clinical feature, precise diagnosis is possible in most cases of disease $(40,41)$

The hCG test approved to be a diagnostic test to the gestational trophoblastic disease, however, any diagnostic test has many test characteristics, including specificity, sensitivity, negative predictive value, and positive predictive value, which vary depending on the cut point used. An ideal diagnostic test would have both high specificity and sensitivity. Unfortunately, like most clinically used biomarkers, hCG-H does not include both of these attributes in the prediction of molar pregnancies. In considering cut point selection, a highly specific threshold value of hCG-H would minimize false positives in already pregnant women. In contrast, a highly sensitive threshold value would minimize false negatives but increase the number of patients with false positive results. The study finding reported higher hCG-H level in molar pregnancy in comparison with normal pregnancy. The presenting study was carried out to explore the significance of hCG-H and other parameters in patients with hydatidiform mole, invasive mole, and choriocarcinoma. Berkowitz ${ }^{(42)}$ reported significantly higher concentrations of hCG-H percentage between molar pregnancy and normal pregnancy, meanwhile, there is no difference hCG-H between molar and invasive molar pregnancy.

In current study revealed that hCG-H was significantly high in patient with molar pregnancy and this result was similar to result done by Cole, 2006 found that, hCG-H (\%) appears to reliably recognize trophoblastic malignancy it is a100\% sensetive marker for distinguishing quiescent GTD from active GTN-choriocarcinoma the data presented appear sufficient to encourage the use of hCG-h as a tumor marker in trophoblastic disease ${ }^{(43)}$.

Also Cole LA1, ,Khanlian SA, Rily JM,ButlerSA 2006,said that hCG_H is a cytokine like molecule produced by cells different from those that mark regular hCG and having a completely separated function it appear to be the modulator of invasion as in implantation of pregnancy, gestational choriocarcinoma and testicular cancer malignancy ${ }^{(44)}$.

Cole LA, 2014, also found that hyperglycosylated hCG in relation to total hCG mark cases intent on developing persistent H.mole (68\%detection at $17 \%$ false
detection).Proportion hyperglycosylated hCG also marks persistent H.mole (100\%detection at $5.1 \%$ false detection). Proportion hyperglycosylated hCG distinguishes choriocarcinoma and gestational trophoblastic neoplasia cases absolutely discriminating aggressive cases and minimally aggressive cases. Proportion hyperglycosylated hCG identify quiescent GTN cases it recognize quiescent cases that become persistent disease (100\%detection at $0 \%$ false positive) ${ }^{(45)}$.

Lisa S kelly1,Steven Birken 2,and David Puett1,2007,the reliably detect aberrant glycosylation of hCG may have great implication for the monitoring and diagnosis of malignant GTN, germ cell tumors, other malignancies and pregnancy complication to become a clinically valuable assay ${ }^{(46)}$.

Cole la1, 2009, regular hCG promotes spiral art angiogenesis and hyperglycosylated hCG control invasion by implanting trophoblastic cells ${ }^{(47)}$.

Guibourdenche J 1 et al, 2010, high level of hCG-H found in maternal sera at first trimester is mainly from invasive event origin reflecting the process of early trophoblastic invasion .

Sandy Chuan, M.D,2014,said that, in patient undergoing assisted reproduction ,

hCG-H is detectable in maternal serum 9 days after egg retrieval IVF-ET cycle, so

hCG-H was superior to traditional hCG and highly predictive of ongoing pregnancies ${ }^{(48)}$.

Our study finding reported higher hCG-H level in molar pregnancy in comparison with normal pregnancy.

The presenting study was carried out to discover the significance of hCG-H and other parameters in patients with hydatidiform mole, invasive mole, and choriocarcinoma.

In this study we use hCG $-\mathrm{H}$ by ELISE test and the result was in pg\ml we didn't use ratio of( hCG-hltotal hCG )because of difference in the technical way and units(total hCG in miu) that's why we cannot do comparison between hCG-H \&total hCG-H but our study show high level of hCG-H in cases with molar pregnancy and other GTN in comparison to normal pregnancy which mean that trophoblastic cell changed to cytotrophoblast or there is increase in percentage of cytotrophoblast in relation to syncytiotrophoblast that's lead to increase hCG-h .but we should remember that's hCG-H is a part of total hCG so it is better to test it in ratio to give good idea about the changes of HCG-H which reflect the cellular behavior.

\section{Conclusion}

1) Serum hCG-H level was higher in patients with invasive mole and patients with choriocarcinoma than patients with gestational trophoblastic disease, so it can be used as a predictor of invasion in patients with invasive mole and choriocarcinoma.

2) Serum hCG-H level can be used in patient with abnormal $\beta$ - hCG after evacuation when it is slowly decreasing or plateau.

\section{Volume 6 Issue 7, July 2017 www.ijsr.net}




\section{International Journal of Science and Research (IJSR) \\ ISSN (Online): 2319-7064}

Index Copernicus Value (2015): 78.96 | Impact Factor (2015): 6.391

3) It is better to measure the ratio hCG-H/total hCG and using uniform method test and units so we can understand the actual changes that happen in invasion

\section{Author Contribution}

Study conception: Dr. Maad Mehdi Shallal

Study design: Dr. Maad Mehdi Shallal, Dr. Najmah M. Miran

Acquisition of data analysis: Dr. Uhood Abbas Obed

Interpretation of data: Dr. Maad Mehdi Shallal Dr. Najmah

M. Miran \& Dr. Uhood A.Obed

Drafting of manuscript: Dr. Uhood Abbas Obed

\section{References}

[1] Silverberg SG and Kurman RJ. Tumors of the uterine corpus and gestational trophoblastic disease. Atlas of tumor pathology, 3rd series, Washington, DC: Armed Forces Institute of Pathology, 1992.

[2] Shih IM, Mazur MT, Kurman RJ. Gestational trophoblastic disease and related lesions. In: Kurman RJ, editor. Blaustein's pathology of the female genital tract. 5th ed. New York: Springer-Verlag, 2002: 11931247.

[3] Scully RE, Poulson H, Sobin LH. International Histological Classification and Typing of Female Genital Tract Tumours. Berlin: Springer-Verlag, 1994.

[4] Matsuura T, Sugimura M, Iwaki $T$, et al. Antimacrophage inhibitory factor antibody inhibits PMSG-hCG-induced follicular growth and ovulation in mice. J Assist Reprod Genet 2002, 19:591-595.

[5] Knittel T, Mehde M, Kobold D, et al. Expression patterns of matrix metalloproteinases and their inhibitors in parenchymal and non-parenchymal cells of rat liver regulation by TNFalpha and TGF-beta1. J Hepatol 1999, 30:48-60.

[6] Berkowitz RS, Goldstein DP, Bernstein MR. Natural history of partial molar pregnancy. Obstet Gynecol 1983; 66:677-681.

[7] Rice LW, Berkowitz RS, Lage JM, et al. Persistent gestational trophoblastic tumor after partial hydatidiform mole. Gynecol Oncol 1990; 36:358-362.

[8] Bracken MB, Brinton LA, Hayashi K. Epidemiology of hydatidiform mole and choriocarcinoma. Epidemiol Rev 1984; 6:52-75.

[9] Aschner B. Ueber die function der hypophyse. Pflug Arch Gest Physiol 1912, 146:1-147.

[10]Fellner OO. Experimentelle untersuchungen uber die wirkung von gewebsextrakten aus der plazenta und den weiblichen sexualorganen auf das genital. Arch Gynakol 1913, 100:641.

[11] Hoshina M, Boime I, Mochizuki M. Cytological localization of hPL, hCG, and mRNA in chorionic tissue using in situ hybridization. Acta Obstet Gynaecol Japonica 1984, 36:397-404.

[12] Cronier L, Bastide B, Herve JC, et al. Gap junctional communication during human trophoblast differentiation: influence of human chorionic gonadotropin. Endocrinology 1994, 135:402-408.

[13] Akoum A, Metz CN, Morin M: Marked increase in macrophage migration inhibitory factor synthesis and secretion in human endometrial cells in response to human chorionic gonadotropin hormone. J Clin Endocrinol Metab 2005, 90:2904-2910.

[14] Murphy G, Reynolds JJ, Whitham SE, et al. Transforming growth factor beta modulates the expression of collagenase and metalioproteinase inhibitor. Euro Molec Biol Org J 1987, 6:1899-1904.

[15] Matsuura T, Sugimura M, Iwaki T, et al. Antimacrophage inhibitory factor antibody inhibits PMSG-hCG-induced follicular growth and ovulation in mice. J Assist Reprod Genet 2002, 19:591-595.

[16] Knittel T, Mehde M, Kobold D, et al. Expression patterns of matrix metalloproteinases and their inhibitors in parenchymal and non-parenchymal cells of rat liver regulation by TNFalpha and TGF-beta1. J Hepatol 1999, 30:48-60.

[17] Qureshi HY, Sylvester J, El Mabrouk M, et al. TGFbeta-induced expression of tissue inhibitor of metalloproteinases-3 gene in chondrocytes is mediated by extracellular signal-regulated kinase pathway and Sp1 transcription factor. J Cell Physiol 2005, 203:34552.

[18] Valmu L, Alfthan H, Hotakainen K, et al. Sitespecific glycan analysis of human chorionic gonadotropin \{beta\}-subunit from malignancies and pregnancy by liquid chromatographyelectrospray mass spectrometry. Glycobiology 2006;16:1207e18.

[19]Hirose T. Experimentalle histologische studie zur genese corpus luteum. Mitt Med Fakultd Univ ZU 1919, 23:63-70.

[20] Kamada M, Ino H, Naka O, et al. Immunosuppressive $30-\mathrm{kDa}$ protein in urine of pregnant women and patients with trophoblastic diseases. Eur J Obstet Gynecol Reprod Biol 1993, 50:219-225.

[21] Pringle K and Roberts C. New light on early postimplantation pregnancy in the mouse: roles for insulinlike growth factor-II (IGF-II)? Placenta 2007, 28:28697.

[22] Cole LA, Butler SA, Khanlian SA, et al. Gestational trophoblastic diseases: 2. Hyperglycosylated hCG as a reliable marker of active neoplasia. Gynecol Oncol 2006;102:151e9.

[23] Cole LA and Khanlian SA. Inappropriate management of women with persistent low hCG results. J Reprod Med 2004;49:423e32.

[24] Hui P, Martel M, Parkash V. Gestational trophoblastic diseases: recent advances in histopathologic diagnosis and related genetic aspects. Adv Anat Pathol 2005; 12:116-25.

[25] Fulop V, Mok SC, Berkowitz RS. Molecular biology of gestational trophoblastic neoplasia: a review. J Reprod Med 2004; 49: 415-22.

[26] Wolfe MW. Culture and transfection of human choriocarcinoma cells. Methods Mol Med 2006; 121: 229-39.

[27] Repiska V, Vojtassak J, Korbel M, et al. DNA analysis in gestational trophoblastic disease. Ceska Gynekol 2003; 68:442-8.

[28] Kichukova D, Piperkov T, Peev B. Difficulties and biases of interpretation in cases of the trophoblast disease. Akush Ginekol (Sofia) 2004; 43:50-3.

[29] Trophoblastic disease. In: Shaw RW, Soutter WP, Stanton SL, (edit). Gynaecology. 3rd ed. Edinburgh: Churchill Livingstone 2002: 248-59.

\section{Volume 6 Issue 7, July 2017 www.ijsr.net}




\section{International Journal of Science and Research (IJSR) \\ ISSN (Online): 2319-7064 \\ Index Copernicus Value (2015): 78.96 | Impact Factor (2015): 6.391}

[30]Loh KY, Sivalingam N, Suryani MY. Gestational trophoblastic disease. Med J Malaysia 2004; 59: 697703.

[31] Tham BW, Everard JE, Tidy JA, et al. Gestational trophoblastic disease in the Asian population of Northern England and Wales. BJOG 2003; 110: 555-9.

[32] Talati NJ. The pattern of benign gestational trophoblastic disease in Karachi. J Pak Med Assoc 1998; 48: 296-300.

[33] Sivanesaratnam V. Management of gestational trophoblastic disease in developing countries. Best Pract Res Clin Obstet Gynaecol 2003; 17: 925-42.

[34] Anuma ON, Umeora OUJ, Obuna JA, et al. Profiling Gestational Trophoblastic Disease in a Tertiary Hospital in South-East Nigeria. Niger J Clin Pract. 2008 Jun;11(2):134-8.

[35] Khairunnisa N, Gulfareen H, Nizamuddin M, et al. Gestational Trophoblastic Disease in Tertiary Hospital Nnewi Southeast Nigeria. Niger Med. J. 2009; 0(4).

[36] Gestational Trophoblastic Disease: Experience at Nawabshah Hospital. J Ayub Med Coll Abbottabad 2009; 21(1) 94-7.

[37] Bugti QA, Baloch N, Baloch MA. Gestational Trophoblastic Disease in Quetta. Patistan J. Med. Res. 2005; 44(2):200 - 4.

[38] Obiechina NJA, Udigwe GO, Obi RA. Molar pregnancy a ten yrar review at Onitsha Nigeria. Journal of Medical Investigation and practice (JOMIP) 2001; 13:26- 31.

[39] Smith HO, Kohorn E, Cole LA. Choriocarcinoma and gestational trophoblastic disease. Obstet Gynecol Clin North Am 2005; 32: 661-84.

[40] Izhar R and Aziz-un-Nisa. Prognosis of gestational choriocarcinoma at Khyber Teaching Hospital, Peshawar. J Ayub Med Coll Abbottabad 2003; 15: 45-8.

[41]Jain KA. Gestational trophoblastic disease: pictorial review. Ultrasound Q 2005; 21: 245-53.

[42] Berkowitz RS and Goldstein DP presentation and management of molar pregnancy. presenation and management of molar pregnancy 2014.

[43] Cole LA, Butler SA, Khanlian SA, Giddings A, Muller CY, Seckl MJ, Kohorn EI Gestational trophoblastic disease: 2 hyperglycosylated hCG as a reliable marker of active neoplasia. Author information; USA hCG service, University of new mexico Health sciences center,2006.

[44] Cole LA, Khanlian SA, Riley JM, Butler SA; Hyperglycosylated hCG in gestational implantation and in choricocorinoma and testicular germ cell malignancy tumorigenesis. USA hCG, department of Obstertrics and Gynecology, university of new mexico health sciences center, Albuquerque, 2006.

[45] Cole LA, Proportion hyperglycosylated hCG: a new test for discriminating gestational trophoblastic disease. USA hCG, service, angel fire NM. 2014.

[46]Lisa S, Kelly, steven Birken, and David Puett, Determination of hyperglycosylated human chorionic droduced by malignant gestational tropholblastic neophlasia and male germ all tumars using a lectin based immunoassay and surface plasmon resonance. department of biochemistry and molecular biology, university of Georgia Athens, GA, 2007.

[47] Cole LA, USA hCG service, hCG and hyperglycosylaled hCG in the establishment and evolution of hemochorial placentation. Women's health research, department of obstetrics and gynecology, university of new mexico, Albuquerque, 2009.

[48] Sandy Chuan M.D., Michael Homer, M.D., Raj Pahdian, Ph.D., Deirder Conway M.D., Gabriel Garzo, M.D., lisa Yeo, C.L.S./E.L.D., and H. lrene Su, M.D., M.S.C.E. Hyperglycosylated human chorionic gonadotropin as an early predictor of pregnancy outcomes after invitro fertilization. San Diego fertility center san diego, California; 2014. 